\title{
Os periódicos franceses na imprensa carioca oitocentista \\ Uma leitura dos editoriais de primeira edição
}

\author{
Amanda Peruchi* \\ Universidade Estadual Paulista (UNESP) \\ Franca - São Paulo - Brasil
}

\section{Resuino}

O desembarque da família real ao Rio de Janeiro, em 1808, deu início a significativo processo de modernização da cidade, impulsionado, entre outras razões, pela necessidade de redefinir seu cenário urbano, pelainstitucionalizaçãodaimprensaepelapresença deestrangeiros de diversasnacionalidades-especialmenteapósoTratado dePazde 1814 que, entre outras medidas, retomou as relações da França com os países europeus e suas respectivas colônias. Neste palco, muitos foram os franceses que vieram para o Rio de Janeiro e instalaram seus diferentes negócios pelas ruas da capital imperial, sobretudo os negócios tipográficos. Seja como proprietários de casas de impressão e/ou livrarias, tais franceses participaram ativamente do mundo dos impressos no Rio imperial, uma vez que se envolveram com a produção e venda de livros, folhetos, panfletos e periódicos, esses, escritos em língua portuguesa e em língua francesa. Deste modo, o principal objetivo deste artigo é dar a conhecer um pouco desses periódicos franceses produzidos na corte, entre os anos de 1827 e 1896, que fizeram parte da imprensa carioca do Oitocentos, para o que listaremos, a partir dos textos dos editoriais de suas primeiras edições, os argumentos dos editores para a produção desses impressos e os principais assuntosque estes editores afirmaram querer abordar em seus respectivos periódicos.

\section{Palaviras-chave}

imprensa carioca; periódicos franceses; século XIX.

* Mestre e Doutoranda em História pela Universidade Estadual Paulista "Júlio de Mesquita Filho", campus de Franca, bolsista CAPES. Contato: amandaperuchi@outlook.com.

Este trabalho é resultado de pesquisa de mestrado (com financiamento CAPES - programa Demanda Social) desenvolvida no Programa de Pós-graduação em História da UNESP/Franca) e no âmbito do Projeto Temático "Escritos sobre os Novos Mundos [...]", financiado pela FAPESP (processo n 13/14786-6). 


\title{
The French newspapers in the carioca press of the Eighteenth A reading of first edition editorials
}

\author{
Amanda Peruchi \\ Universidade Estadual Paulista (UNESP) \\ Franca - São Paulo - Brasil
}

\section{Abstiract}

The royal family landing in Rio de Janeiro in 1808 began a significant process of modernization, driven by the need to redefine its urban setting, by institutionalizing the press and by the presence of foreigners of different nationalities - especially after the Treaty of Peace (1814) which restablished the french relantionship with European countries and their respective colonies. At this point, many were the French who came to Rio de Janeiro and settled their different businesses through the streets of the imperial capital, especially typographical businesses, during the nineteenth century. As owners of printing houses and/or bookstores, such Frenchmen actively participated in the printing world on the Imperial Rio de Janeiro, as they engaged in the production and sale of books, pamphlets and periodicals, written in Portuguese and in French. Thus, the main objective of this article is to make known a little of these French periodicals produced in the court, between theyears of 1827 and 1896, that were part of the Carioca press of the Eightieth, for which we will list, from the texts of the editorials of their first editions, the publishers' arguments to produce these printed matter, and the main subjects that these editors claimed they wanted to address in their respective journals.

\section{Keywords}

press in Rio; French newspapers; XIX century. 


\section{Introdução}

Em abril de 1827, Pierre Plancher redigiu e publicou em sua tipografia, localizada na rua do Ouvidor, n. 95, o primeiro periódico escrito em francês na cidade do Rio de Janeiro: o L'Indépendant. O impresso, que logo em sua primeira edição apresentou as razões e expectativas de seu aparecimento, durou pouco mais de dois meses e contou somente com 10 edições. Apesar disso, Plancher registrou no L'Indépendantdiversoscomentáriossobrecomoumafolhafrancesapublicada na capital do Império poderia ser importante para os moradores e contribuir com essa ainda incipiente imprensa carioca. Iniciada por Pierre Plancher, a produção de periódicos em língua francesa na cidade do Rio de Janeiro se repetiu ao longo de todo o Oitocentos, e muitasforamasjustificativasassinaladas peloseditoresquepodemser mapeadasapartirdostextosdeapresentaçãodessesimpressos.Tendo comobaseumlevantamento realizadonosacervos daHemerotecaDigital(http://bndigital.bn.gov.br/hemeroteca-digital/)-siteassociado à Biblioteca Nacional - e do Google Books ${ }^{1}$ foram contabilizados, até omomento,22títulos de periódicosfranceses produzidos nacapitaldo Império no século XIX, mais especificamente entre os anos de 1827 e 1896. Desses títulos, alguns tiveram um pequeno número de edições, enquanto outros chegaram a figurar por mais de nove anos o cenário dos impressos na corte. A partir de uma leitura dos editoriais de apresentação, ${ }^{2}$ este artigo tem como principal objetivo listar algumas das razõesquelevaramoseditores dos periódicosfranceses a publicá-lose analisar quais eram os assuntos que esses redatores afirmaram querer

1 Um estudo que nos auxiliou no levantamento dos jornais franceses publicados no Rio de Janeiro foi odopesquisadorGondimdaFonseca, publicadoem 1941,Biografiadojornalismocarioca(1808-1908).

2 Todos os editoriais das primeiras edições dos periódicos franceses disponíveis foram traduzidos pormimem um outro trabalho, ver: PERUCHI, Amanda. No rastro dos jornais franceses oitocentistas. Os anúncios e a vida social no Rio de Janeiro (1827-1896). 2016. 169 f. Dissertação (Mestrado em História). Faculdade de Ciências Humanas e Sociais, Universidade Estadual Paulista "Júlio de Mesquita Filho", Franca, 2016. 
abordar em suas páginas, a fim de dar a conhecer um pouco dessas folhas francesas que fizeram parte da imprensa carioca no Oitocentos.

\section{Dos porquês dos editores}

Entre outros acontecimentos, o envolvimento dos franceses com a arte impressora na corte parece ter sido impulsionado pela abertura das terras brasileiras aos estrangeiros, em 1808, e peloTratado de Paz, em 1814, - acordo que versava sobre a saída de Napoleão do governo francês, por qual acordo se restabeleciam as fronteiras francesas e se retomavam as relações da França com os países europeus e suas respectivas colônias, como é o caso de Portugal e Brasil. Além disso, com o desembarque da família real no Rio de Janeiro, a cidade, por tornar-se sede da coroa portuguesa no Brasil, começou a passar por uma série de transformações que visavam a melhorar a urbe carioca e abriuespaço para a vinda deprofissionais estrangeiros de diversasáreas comprometidos com as atividades comerciais. ${ }^{3}$ Neste palco, muitos foram os franceses que perceberam essa possibilidade e vieram estabelecerseusnegóciostipográficose/oulivreiros.Umdospersonagens de maior destaque foi Pierre Constant Dalbin, que chegou ao Rio de Janeiro em 1818 e acabou se tornando uma importante peça do comércio livreiro do início do século XIX. Dalbin costumava vender em suaCasadeP.C.DalbineC. obras deautoresestrangeiros, sobretudode Cervantes, Camões e Fenélon para a divulgação, entre os homens da corte, de alguns dos livros mais célebres daquele tempo. ${ }^{4}$

Pouco tempo depois, em 1824, foi a vez do mencionado Pierre Plancher aportar na capital do Império. Fugindo da recente ascensão de Carlos X ao trono francês, Plancher veio para o Rio de Janeiro e

3 MARTINS, Ana Luiza Martins. Presença imigrante francesa no Brasil: entre visões do paraíso e mercado de trabalho. In: VIDAL, Laurent. LUCA, Tania Regina de (orgs.). Franceses no Brasil séculos XIX e XX. São Paulo: Editora Unesp, 2012, p. 29.

4 NEVES, Lúcia Maria Bastos Pereira das. Livreiros franceses no Rio de Janeiro: 1799-1824, p. 7. Disponível em: <http://www.portcom.intercom.org.br/pdfs/bb3aea30006796253008218e5bdda0c1. pdf. $>$ Acesso em: 30/05/2015. 
instalou um negócio tipográfico na corte, ${ }^{5}$ do qual já era proprietário na França. Antes mesmo de produzir o L'Indépendant, Plancher publicoumuitosoutrosimpressos, asaber:aConstituiçãoPolíticadolmpério (1824);OSpectadorBrasileiro(1827), ${ }^{6}$ primeiroperiódico produzidoem uma casa tipográfica particular reconhecida pela corte - isto é, fabricado fora da Impressão Régia, mas atestado por seuscensores--, entre outros. ${ }^{7}$ Oconteúdo desuas produçõesquasesempremostravadefender ou exaltar a figura do Imperador brasileiro, em comentários sobre as ações políticas do monarca ou sobre as atividades e as festividades de sua vida pessoal, o que abriu espaço para uma boa relação entre $D$. Pedro I e o francês. Aliás, a relação entre os dois era tão favorável que Plancher chegou a ganhar do monarca o título de "impressor de sua majestadeolmperador"-títuloessecontinuamentecitadonasúltimas páginas de todasas obras. ${ }^{8}$ Contavam-se, então, a produção de muitos impressos e quase três anos de comércio impressor na corte quando Plancher decidiu iniciar uma nova empreitada: redigir e publicar um periódico escrito totalmente em francês na cidade do Rio de Janeiro.

Por acreditar que esse tipo de publicação poderia causar "certa surpresa ao público", Plancher registrou, em seu editorial de apresentação do L'Indépendant, queera necessário explicaraos moradores da cidade os porquês do surgimento de uma fol ha francesa naquela localidade. ${ }^{9}$ Segundo ele, a produção de um periódico escrito em francês

5 BERGER, Paulo. A Tipografia no Rio de Janeiro: impressores bibliográficos 1808-1900. Rio de Janeiro: Cia. Industrial de Papel Pirahy, 1984, p. 15 e HALLEWELL, Laurence. O Livro no Brasil: sua história. Trad. Maria da Penha Villalobos, Lólio Lourenço de Oliveira e Geraldo Gerson de Souza. São Paulo: EDUSP, 2012, p. 148.

6 Depois deencerradas as publicações do Spectador Brasileiro Plancher comprou os direitos dojornal Diário Mercantil de Francisco Manuel Ferreira \& Cia e, antes de sua primeira edição, mudou o nome do periódico para Jornal do Commercio dando início, assim, a um dos principais jornais brasileiros de todo o século XIX.

7 MOLINA, Matías M. História dos jornais no Brasil: Da era colonial à Regência (1500-1840). São Paulo: Companhia das Letras, 2015, p. 233-235 e HALLEWELL, Laurence. Op. Cit., p. 153.

8 MOLINA, Matías M. Op. Cit., p. 235.

9 L'INDÉPENDANT: feuille de commerce, politique, et litteraire. Rio de Janeiro, n. 1, 21 de abril de 1827, p. 1. As citações foram por mim livremente traduzidas. 
na corte era, antes de mais nada, algo urgente e indispensável, pois toda nação que desejasse ter cidadãos mais cultos ou que fosse discutir sobre o futuro do país precisava da língua francesa. Na visão de Plancher,independentementedanacionalidade,eraesteoidiomaque deveria ser utilizado para a instrução ou para as sábias reflexões dos homens. Além disso, levando-se em consideração o sucesso dos impressos franceses em outros países - como Alemanha, Itália e Holanda -, um jornal francês cairia muito bem no Rio de Janeiro, considerado a "verdadeira metrópole da América do Sul, ${ }^{10}$ o ponto central das relações entre a Índia, a Europa e o Grande Oceano Pacífico". ${ }^{11}$ Outra razão explorada por Plancher, e devido muito provavelmente à sua boa relação com D.Pedrol, era que oL'Indépendant deveria ser"escrito sabiamente nos princípiosmonárquicose honestamente constitucionais" e se apresentar como "uma arena sempre aberta" à "polêmica livre" e "decente", em que as "úteis verdades" seriam levadas ao públicoleitor.OL'Indépendant,segundoseueditor,tambémnãoveicularia apenas as notícias de interesse pessoal deseu proprietário, porqueum de seus objetivos era ser um palco aberto para a discussão dos mais variados assuntos. $^{12}$

Portodosessesmotivos, paraPlancher, seoscariocasquisessemrealizarsaudáveisdiscussões-assimcomofaziamosingleses,osalemães, ositalianoseosholandeses-eles precisavamassumiraimportânciada língua francesa e compreender os benefícios que uma folha francesa no Rio de Janeiro poderia oferecer. ${ }^{13}$ Esse editor francês, como adian-

10 O Rio de Janeiro foi, do século XVII ao XIX, um lugar de parada das embarcações que viajavam do Ocidente para o Oriente, ou vice-versa. Desse modo, muitas foram as notícias que chegaram a seu porto; por isso, publicar um jornal naquela cidade era sinônimo de estar perto das informações dos dois lados do mundo. FIGUEIREDO, Cláudio; SANTOS, Nubia Melhem; LENZI, Maria Isabel Ribeiro. O Porto e a cidade: o Rio de Janeiro entre 1565 e 1910. Editora: Rio de Janeiro; Casa da Palavra, 2005 e MENEZES, Pedro da Cunha; BANDEIRA, Júlio. O Rio de Janeiro na rota dos Mares do Sul. Rio de Janeiro: Andrea Jakobsson Estúdio, 2004.

11 L'INDÉPENDANT, 1827, n. 1, 21 de abril de 1827, p. 1.

12 L'INDÉPENDANT, 1827, n. 1, 21 de abril de 1827, p. 1.

${ }^{13}$ L'INDÉPENDANT, 1827, n. 1, 21 de abril de 1827, p. 1. 
tamos, embora tenha sido o primeiro não esteve sozinhona produção dos periódicos franceses na capital do Império. Durante todo o século XIX, muitas outras folhas francesas conquistaram as ruas da cidade imperial, e seus editores - porta-vozes de que seu público seria os que desejavamestarenvolvidoscomumaculturamaisintelectualizada-tinhamoobjetivo deinstruirtodososmoradores dacidade, querfossem franceses, brasileiros ou até mesmo portugueses.

Meses depois e com uma justificativa semelhante à de Pierre Plancher, E.Sevène,editordol'Échodel'AmériqueduSud (1827-1828), escreveu que o grande propósito de seu periódico era "sustentar os princípios da legislação que os novos governos da América do Sul proclamaram após a sua independência", ou seja, contribuir para a existência deumpaísindependentedePortugal, masainda monárquico. ${ }^{14}$ Ele argumentava que defenderia os princípios de uma nação livre e que não mediria esforços para pontuar constantemente os proveitos que D. Pedro I poderia oferecer à nação brasileira. Os argumentos de Sevène se aproximam dos que foram apresentados por Plancher; isso pode serexplicado pelofato deo L'Écho del'Amérique du Sud também serproduzidopelalmprimerielmpèrialedeP.Plancher-Seignot. ${ }^{15}$ Alémdisso, ainda que tenha procurado ressaltar que Plancher não faria parte da redaçãodol'Échodel'AmériqueduSud,Sevèneassumiuosassinantesdo recém-extintoL'Indépendanteprometeuquenãoosiriadeixardesamparados, oque pode serindício dequeambososeditorescompartilhavam de muitos ideais. Também em seu editorial de apresentação, Sevèneregistrouqueuma outra razão para a publicação de seu periódico era a localização geográfica do Rio de Janeiro; a cidade, conforme ele destacou, era o"ponto central das relações entre a América do Norte, a Europa, a Índia e o Oceano Pacífico". ${ }^{16}$ Novamente concordando

\footnotetext{
${ }^{14}$ L'ÉCHO DE L'AMÉRIQUE DU SUD: journal politique, commercial e littéraire. Rio de Janeiro, n. 1, 30 de junho de 1827, p. 1.

${ }^{15}$ Foi apenas no ano de 1827 que o L'Écho de l'Amérique du Sud foi publicado pela tipografia de Pierre Plancher. No ano seguinte, passou a ser produzido pela Imprimerie de L'Écho de l'Amérique du Sud, conforme pode ser verificado nos números de 1828.

${ }^{16}$ L'ÉCHO DE L'AMÉRIQUE DU SUD, n. 1, 30 de junho de 1827, p. 1.
} 
com a opinião de Plancher, Sevène pontuou a importância geográfica do Rio para a chegada de notícias dos dois lados do mundo. De acordo com sua observação, a localização da cidade fazia com que as informaçõesentreoocidenteeoorientechegassemmaisrapidamente para ambos os lados, o que provavelmente contribuiria para o sucesso de sua empresa. ${ }^{17}$

Com pretensões e motivos muito parecidos, o jornal de E. Sevène teve uma duração muito maior que o de seu conterrâneo Plancher. Tendo sido publicado pela primeira vez em 30 de junho de 1827, o L'Échodel'AmériqueduSudcontou com74ediçõesefoifinalizadoem 29 demarço de 1828, algo que pode ser considerado surpreendente para um jornalescrito inteiramenteem francês, ainda mais porque durante as primeiras décadas de imprensa no Império grande parte das folhas brasileiras não conseguia ultrapassar o entusiasmo de seus números iniciais. Arespeitodessesucesso dosimpressosfranceses, observamos que na primeira metade do Oitocentos os cariocas ainda veriam surgir mais sete títulos franceses, chegando-se a um total de nove periódicossomentenesteperíodo.Dessestítulos, oLeCourrierdu Brésil(18281830), oLeMessager(1831-1833), a RevueFrançaise (1839-1840) eoLe Nouvelliste(?-1848) ${ }^{18}$ foram publicados pormaisdedoisanos,enquanto osdemais-aRevueBresilienne(1830), oL'Alcyon(1841)eoL'ÉchoFrançais (1849) - encerraram suas produções em seus anos iniciais.

Já na segunda metade do século XIX, outros 13 títulos franceses foram lançados no mundo dos impressos cariocas. O mais duradouro foi o Courrier du Brésil, ${ }^{19}$ editado por Ad. Hubert, publicado pela pri-

17 L'ÉCHO DE L'AMÉRIQUE DU SUD, n. 1, 30 de junho de 1827, p. 1.

18 HácertaimprecisãosobreadurabilidadedoLeNouvelliste.SegundoGondimdaFonseca, nocatálogo da Biblioteca Nacional só aparecem os números deste jornal francês a partir do ano 1847, que era, de acordo com a própria data do jornal, o décimo primeiro ano de vida do jornal. Portanto, ele afirmou que o Nouvelliste teria sido publicado pela primeira vez em 1837. Cf. FONSECA, Gondim da. Op. Cit., p. 303.

${ }^{19}$ É importante aqui destacar o texto de Letícia Gregório Canelas, O Courrier du Brésil e o conflito entre associações francesas no Rio de Janeiro, publicado em 2009, no livro organizado pelos historiadores Laurent Vidal e Tania Regina de Luca, Os Franceses no Brasil - séculos XIX e XX. 
meira vez em 15 de setembro de 1854 e finalizado em 1862, contando com aproximadamente 360 edições ao longo desses nove anos. Em seguida, o Le Messager du Brésil e o Ba-ta-clan aparecem como os que tiverammaiorduração, permanecendo porvolta desete(1878-1884)e cincoanos(1867-1871), respectivamente.Osdemaisocuparamasruas da cidade imperial por quase ou um pouco mais de um ano-L'Écho de I'Atlantique(1858);Figaro-Chroniqueur(1859);LeNouvelliste(1863);'Lavenir duBrésil (1885); L'Empire du Brésil (1887); L'Écho du Brésilet del'AmériqueduSud(1859-1860);LaGazetteduBrésil(1867-1868);FranceetBrésil (1874-1875);LeGil-Blas(1877-1878);eoAlmanachdeBrésilRepublicain (1895-1896). ${ }^{20}$ Não cabe aqui comparar a quantidade e a durabilidade dos jornais franceses em relação aos jornais brasileiros; no entanto, dos 22 títulos disponíveis nos acervos consultados, todospassaram de suasprimeirasedições eforampresentesemquasetodasasdécadasdo século XIX, fazendo parte do crescimento e do desenvolvimento da imprensa carioca desta época.

Pelos escritos dos editoriais de primeira edição, as folhas francesas produzidasnasegundametadedoOitocentos, a exemplo das publicadas na primeira metade, evidenciam também as justificativas de seus editores. Em maio de 1859, Altève Aumont, editor do L'Écho du Brésil etdel'AmériqueduSud, fundou, segundo suas próprias palavras,"uma nova folha francesa no Rio de Janeiro com a firme convicção de que [poderia ser útil] aos [seus] conterrâneos no Brasil, ao Brasil e às pessoas envolvidas com a Europa e com a América do Sul".21 Demonstrando, pois, a certeza de que o novo jornal seria de grande interesse aos moradores - brasileiros ou franceses -, o editor sintetizou suas expec-

Nele a autora realizou um estudo sobre este jornal francês na corte e a relação que ele manteve com algumas das principais figuras do comércio francês na corte. CANELAS, Letícia Gregório. O Courrier du Brésil e o conflito entre associações francesas no Rio de Janeiro. In:VIDAL, Laurent. LUCA, Tania Regina de (orgs.). Op. Cit., p. 289-318.

${ }^{20}$ A contagem das edições e a durabilidade de cada um dos títulos franceses aqui elencados teve como base as informações disponíveis no acervo da Hemeroteca Digital ou do Google Books.

${ }^{21}$ L'ÉCHO DU BRÉSIL ET DE L'AMÉRIQUE DU SUD: ce journal parait tous les dimanches. Rio de Janeiro, n. 1, 1 de maio de 1859, p. 1. 
tativasacercadessanovatarefa.Aumont,emseguida, acrescentouque oL'ÉchoduBrésilet del'AmériqueduSudnãosurgiapara seradversário dos outros impressos franceses da corte, pois ele desejava uma vida longa e próspera aos periódicos já existentes, e que, entretanto, diferenciando-se dos demais, o seujornal seria o marco de um novo fôlego para asfolhasfrancesas porque, antes detudo, ele procuraria defender osinteressesdeseusconterrâneos;oL'ÉchoduBrésiletdel'Amériquedu Sud, assim, objetivava ser o"eco da opinião geral, mas sem esquecer que ele [era] francês".22

Essanoção de queos periódicosfranceses deveriamservirbrasileiros efranceses, mas sem esquecer sua verdadeira nacionalidade, tambémfezpartedoposicionamentodoeditordoLaGazetteduBrésil,Louis Sauvages. Em 1867, ele afirmou em seu editorial de apresentação que procuraria ser constantemente útil aos brasileiros e a seus compatriotas, uma vez que "um jornal francês publicado no Rio de Janeiro [era] chamado a fazer um serviço a todos"e que para alcançar este objetivo "ele deve[ria] se manter em boas relações, em boa inteligência com todo o mundo", ainda mais porque sua produção tinha "o objetivo de aumentar as relações entre o Brasil e a Europa, particularmente com a França".23 Esse ímpeto de manter um bom relacionamento com todos os moradores da corte e com os demais impressos ali publicados, todavia, não seria um obstáculo para que o La Gazette du Brésil mostrasse reação casofosseatacado em outrasfolhas da cidade.Sauvages, acerca disso, registrou que seu impresso responderia rapidamente às ofensas recebidas para impedir que "desrespeitassem a sua opinião".24

Apesar de ter elencado esses argumentos comojustificativas para a produção de sua folha francesa na capital do Império do Brasil, Sauvagesdestacouqueograndeeilustreobjetivo deseuempreendimento era contribuir ativamente com a colonização do Brasil. O Império do

22 L'ÉCHO DU BRÉSIL ET DE L'AMÉRIQUE DU SUD, n. 1, 1 de maio de 1859, p. 1.

${ }^{23}$ LA GAZETTE DU BRÉSIL: journal politique, commercial, agricole et littéraire. Rio de Janeiro, n. 1, 23 de abril de 1867, p. 1.

${ }^{24}$ LA GAZETTE DU BRÉSIL, n. 1, 23 de abril de 1867, p. 1. 
Brasil,segundocomentou, tinha"umanecessidadeabsoluta"degente disposta a atuar nos lugares ainda muito pouco povoados; era preciso que "as cidades, os vastos campos, os ricos vales, as belas montanhas, que todo o país"atraísse os melhores colonizadores para as terras brasileiras, onde "qualquer província [era] maior que a França". Para resolveressasituação, Sauvageselencou equalificou,emseueditorialde primeira edição, os cinco povos que, em sua opinião, poderiam "vantajosamentecolonizaroBrasil:osalemães, os portugueses, osingleses, os americanos e os franceses".25

Os alemães, para o editor, nem precisavam ser apresentados, porque em relação à colonização"eles eram considerados os melhores do mundo". Os portugueses, porsua vez, também játeriam oferecido provassuficientes desuaeficiência,eoLaGazetteduBrésilfacilmenteenumeraria todas as qualidades dos "descendentes de Vasco da Gama". Sempreúteis elivres de incertezaseramoscolonos ingleses.Jáosamericanos estavam divididos em dois grupos, eera preciso interpretá-los corretamenteparaummelhoraproveitamentodesuashabilidades.Os americanos do Norte, de acordo com o editor, "dificilmente conseguiriam se estabelecer no Brasil", pois"a raça anglo-saxônica, seus modos e sua natureza se [opunham] ao sucesso da colonização".26 Por outro lado,"os americanos do Sul, provenientes de uma raça latina, [tinham] religião,modosehábitos"maisparecidoscomos dosbrasileiros.Assim, para beneficiar-se desta situação, o Brasil poderia "oferecer uma parcela a mais da hospitalidade para esses [americanos] orgulhosos e resolutos". A França, por fim, poderia igualmente ser de muita utilidade. SegundoSauvages, existiambraçosfranceses"maisdoquesuficientes, para a cultura da terra" brasileira, principalmente se fossem considerados"os agricultores bascos, os do Sul, os da região de Bigorra, os do Franco-Condado, os da Normandia, etc.". Somado a isso, os franceses também seriam úteis com seus imensos serviços de indústria e de co-

${ }^{25}$ LA GAZETTE DU BRÉSIL, n. 1, 23 de abril de 1867, p. 1.

${ }^{26}$ LA GAZETTE DU BRÉSIL, n. 1, 23 de abril de 1867, p. 1. 
mércio, ${ }^{27}$ serviçosesses, inclusive, muito bem conhecidos pelos moradores da corte desde o início do século XIX - conforme destacamos - quandofrancesesdediferentesatividadescomerciaisaportarameespalharam suas lojas pelas ruas do centro da cidade do Rio de Janeiro. ${ }^{28}$

Essa questão da colonização não se repetiu de maneira tão detaIhada nos editoriais de apresentação dos demais periódicos franceses publicados na corte - como no caso do La Gazette du Brésil -, mas foi um dos temas mais recorrentes da administração do governo brasileiro, especialmente a partir de meados do século XIX. Nesse momento, muitas foram as discussões sobre a chegada dos estrangeiros e sobre como eles poderiam ser utilizados na ocupação das terras ou mesmo no comércio das demais cidades do Império, e não apenas no Rio de Janeiro. ${ }^{29}$ Ao fazerem parte da imprensa carioca oitocentista, era de esperarqueoseditoresdasfolhasfrancesastambémdiscutissemtemas caros ao desenvolvimento e ao crescimento do Brasil. Talvez teria sido por esse motivo que o editor do La Gazette du Brésil mostrou que seu principal objetivo era participar e comentar sobre a colonização do território brasileiro.

Outra justificativa assinalada pelos editores dos jornais franceses foia necessidade de melhorara imagem dosfranceses no Rio de Janeiro, assim como em outras cidades do país. Segundo explicou o redatordoFrance et Brésil em seu texto deapresentação,osestrangeirosde outrasnacionalidadestinham diversosperiódicosquedefendiamseus respectivosinteresses, algo quenãoocorriacomosfranceses. Osingleses, porexemplo,tinhamoAnglo-Brazilian-Times,osalemães,oAllgemeineDeutscheZeitung,eosportuguesesfaziamusodetodasasoutrasfolhas publicadas no Rio de Janeiro, uma vez que o "idioma nacional [era]

${ }^{27}$ LA GAZETTE DU BRÉSIL, n. 1, 23 de abril de 1867, p. 1.

${ }^{28}$ MARTINS, Ana Luiza Martins. Presença imigrante francesa no Brasil: entre visões do paraíso e mercado de trabalho e DUMONT, Juliette. Preciosos súditos, emigrantes atravancadores: a França e os franceses no Brasil no início do século XIX. In: VIDAL, Laurent. LUCA, Tania Regina de (orgs.). Op. Cit.

${ }^{29}$ COSTA, Emília Viotti da. Política de terra no Brasil e nos Estados Unidos. In: COSTA, Emília Viotti da. Da Monarquia à República: momentos decisivos. São Paulo: Editora UNESP, 2010, p. 171-195. 
comum para as duas nações. A França, sozinha, fica[va] isolada da grande confraternização dos povos". ${ }^{30}$ Com o propósito de defender osinteressesdosfrancesesquemoravamnacorte,interessesessesque na maioria das vezes estavam prejudicados, o editor do Franceet Brésil disse que publicava sua folha com a firme convicção de que ela não mais deixaria os franceses isolados, assumindo uma função até então desprezada ou ineficientemente realizada pelos periódicos franceses publicados na corte.

Essa opinião do redator do France et Brésil em relação à imagem da França e dos franceses no Brasil já tinha sido apresentada - quase duasdécadasantes, maisespecificamenteem 1858-peloseditoresde outrojornalfrancês:oL'Échodel'Atlantique.Semevidenciarosporquês dessa péssima reputação, A. Deyme \& C. registraram que era da competência dos jornais franceses a tarefa de mudar a visão altamente degradada dos franceses e da França no Brasil. ${ }^{31}$ Do mesmo modo, eles tambémprocuraramenfatizarqueoL'Échodel'Atlantiqueficaria“longe dos partidos" políticos porque acreditavam que essa era a "postura [mais] correta" de um jornal francês produzido na corte e porque, igualmente, desejavam que o periódico fosse apresentado como"um órgão benéfico"para todosos brasileiros,importante para estabelecer uma amizade sincera não só com os moradores da ca pital, mas com os de todo o Império. Os editores, por fim, assinalaram que, tal como na folhadeSauvages, ostextos doL'Écho del'Atlantique seriamabertosàs diferentes opiniões, mas que seria preservada, casofosse preciso, uma postura a favor dos franceses e da França para que sua nação fosse bem representada. ${ }^{32}$

Em 1877, mais uma vez a França foi lembrada como uma das razões para a publicação de um impresso francês na corte. Segundo anotou Fantasio, o editor do Le Gil-Blas, "eis que a emoção inseparável

\footnotetext{
${ }^{30}$ FRANCE ET BRÉSIL: journal français. Rio de Janeiro, n. 1, 2 de setembro de 1874, p. 1.

${ }^{31}$ L'ÉCHO DE L'ATLANTIQUE: organe des intérêts franco-brèsilliene, paraissant les dimanche et jeudi de chaque semaine. Rio de Janeiro, n. 1, 10 de janeiro de 1858, p. 1.

32 L'ÉCHO DE L'ATLANTIQUE, n. 1, 10 de janeiro de 1858, p. 1.
} 
de um primeiro número [lhe] agarra[va] à garganta", pois era com muito prazer que, "de vez em quando" ele viria "contar o que se passa[va] do outrolado do oceano, em um pequeno pedaço de terra"chamado França. ${ }^{33} \mathrm{~A}$ proposta do jornal, além disso, era unir brasileiros, franceses que moravam no Rio e franceses da França em uma única comunidade com ideias semelhantes, a fim de construir um "sublime edifício da Liberdade". O editor do Le Gil-Blas, nesse sentido, pediu licença aos demais impressos da corte para poder falar abertamente sobre a República e a Liberdade francesa, das quais ele não abriria mão e nem deixaria de as defender nas terras brasileiras. ${ }^{34}$

De maneira geral, muitas foram as razões que levaram esses homens franceses, vindos do outro lado do Atlântico, a produzir periódicos redigidos em língua francesa na cidade do Rio de Janeiro no Oitocentos.Seusanseios-comovimos, quasesemprecompartilhados - iam desde recuperar e manter uma boa imagem da França e dos franceses no Rio de Janeiro, passando pela boa localização geográfica da capital do Império, que permitia mais rápida e mais eficiente troca de informações com todos os cantos do mundo, até chegar ao objetivo de preservar um bom relacionamento entre os franceses e os cariocas, oferecendoconstantementenotíciaseinformaçõesatodosos habitantes da corte, quaisquer que fossem suas nacionalidades. Fora isso, a noção de que o periódico deveria instruir a população também foi um tema retomado nos textos dos editoriais, especialmente porque destacavam que, nas folhas francesas, as opiniões seriam frontalmente debatidas - diferentemente do que ocorria nos diários brasileiros, segundo os próprios redatores dos jornais franceses. Enfim, conhecer e mapear algumas das justificativas dos editores das folhas francesas publicadas no Rio de Janeiro no século XIX é ter acesso aos registros de uma imprensa estrangeira que se produziu na corte eque contribuiu, de uma maneira ou de outra, com a imprensa carioca oitocentista e com as discussões acerca da nação e do país em formação.

${ }^{33}$ LEGIL-BLAS:journal politique, satyrique et artistique. Rio de Janeiro, n. 1, 14 de outubro de 1877, p. 1 . ${ }^{34}$ LE GIL-BLAS, n. 1, 14 de outubro de 1877, p. 1. 
Assim como os textos de apresentação das primeiras edições dos periódicos franceses registraram as razões assinaladas pelos editores parasuaprodução,elestambémrevelavamosassuntosqueessesmesmos editores desejavam abordar em suas folhas. Essas anotações, a exemplo das justificativas, mostram a expectativa dos editores com suaspublicaçõesbemcomoevidenciamoposicionamentodecadaimpresso em relação aos acontecimentos não só da corte, como de todo o mundo.

\section{Dos conteúdos abordados}

Continuando com a leitura dos editoriais de primeira edição dos periódicos franceses produzidos no Rio de Janeiro, observamos que o editordol'ÉchoduBrésiletdel'AmériqueduSud,AltèveAumont, destacou que seu impresso seria dividido da seguinte maneira: uma parte dedicada às notícias do Brasil, às da América do Sul e às da Europa; uma outra com informações das atividades comerciais e do movimento de mercado; e uma última, às variedades, ou melhor, aos escritos de entretenimento, sobretudo crônicas, piadas e alguns artigos científi$\cos ^{35}$ Sobreas notícias do Brasil, segundo Aumont, oL'Écho du Brésilet del'Amérique du Sud teria um"grandeespaço"paraas"Variedades brasileiras" e para a "Galeria biográfica", uma vez que o país era "pouco e mal conhecido" pelos europeus que o habitavam e também porque "uma das várias maneiras de atrair atenção a esse país [era] tornar conhecidas as suas instituições, a sua administração e os seus homens notáveis". Para esta mesma finalidade, o jornal traria semanalmente uma"HistóriadetodasascolôniasfundadasnoBrasil"e"Estudossobretodosos ramosdaadministração,sobreocomércio,aindústria,aagricultura,asfinanças,a marinhaeoexército,ajustiça, aescravidão,ainstruçãopública, etc.,etc.". 36

${ }^{35}$ L'ÉCHO DU BRÉSIL ET DE L'AMÉRIQUE DU SUD, n. 1, 1 de maio de 1859, p. 1.

${ }^{36}$ L'ÉCHO DU BRÉSIL ET DE L'AMÉRIQUE DU SUD, n. 1, 1 de maio de 1859, p. 1. Grifos do autor. 
Essa preocupação em falar sobre o Brasil e suas novidades foi uma tópica recorrentedasanotações doseditores dos periódicosfranceses da corte desde o início de suas produções. Em 1827, E. Sevène, a esse respeito, registrou que seu jornal ofereceria muitos textos sobre esta "grande e bela parte do continente americano".37

[...] um vasto campo de observações sobre tudo o que contém em seu seio, seja considerando-seasriquezas deseu solo, de suas minas deouroe de diamantes, sejaexaminando-seasincontáveisvariedades deseus produtosagrícolas.Bem que a França possui uma massa de conhecimentos sobre tudo o que interessa ao comércio, à indústria eà agricultura do Brasil; nós acreditamos que é nosso dever fornecer fiéis exposições sobre as três fontes da felicidade do público felizmente, sepudermos retificarparanoções exataseverdadeirasalgunserros que estão deslizando no espírito de nossos compatriotas sobre a riqueza dos estados americanos e sobre os perigos das fortunas que as mudanças políticas ocasionaram. ${ }^{38}$

Para um melhor entendimento e aproveitamento das terras brasileiras, Sevène enfatizou que falaria das riquezas do país e do que seuscompatriotaspoderiamusardesta partedocontinenteamericano, além detambémmencionarosperigosqueesseprósperoterritóriopoderia oferecer a seus moradores. Destacou que era muito importante trazer as notícias do Brasil nas páginas de seu periódico porque era necessário que os franceses moradores das terras brasileiras ficassem informados de seus acontecimentosmaisatuais, ainda que muitos deles já estivessem familiarizados com a situação do país antes de atravessarem o Atlântico. ${ }^{39}$

Em 1858, baseando-se nos assuntos que deveriam ser discorridos em suas publicações, os editores do L'Écho de l'Atlantique, A. Deyme \& C., escreveram que, se o "jornal tive[sse] o sucesso" que eles esperavam, "seguindo dia após dia a discussão de todas as questões

${ }^{37}$ L'ÉCHO DE L'AMÉRIQUE DU SUD, n. 1, 30 de junho de 1827, p. 1.

38 L'ÉCHO DE L'AMÉRIQUE DU SUD, n. 1, 30 de junho de 1827, p. 1.

39 L'ÉCHO DE L'AMÉRIQUE DU SUD, n. 1, 30 de junho de 1827, p. 1. 
interessantes", eles conseguiriam fazer "o Brasil mais conhecido".40 Compartilhando desteobjetivo, o editor doL'avenir du Brésil,em 1885, asseverou que em seu periódico falaria do Brasil para torná-lo conhecido aos franceses, aos europeus e que procuraria propagar"o conhecimento de seus tesourose dos recursos"disponíveis, registrandopara "o maior número possível de trabalhadores que deseja[vam], senão a fortuna, pelo menos uma vida fácil e tranquila", a verdadeira face das terras brasileiras. ${ }^{41}$

Damesmamaneira,em 1874,oeditordoFranceetBrésil-periódico quesurgiu, como dissemos, com opropósito demelhoraraimagem da França e dos franceses no Brasil - afirmou que a sua intenção também era tornar o Brasil conhecido pelos europeus que habitavam a corte. Para tanto, o jornal versaria sobre os “homens do Estado, o comércio, a indústria, a colonização, a instrução, as vozes de comunicação, a justiça, a religião", entre outros assuntos que concorreriam para que particularmente os franceses se relacionassem com os acontecimentos da cidade. Os denominados homens do Estado, isto é, os homens envolvidos com o governo imperial, apareciam em primeiro lugar na lista do editor do France et Brésil. Isso porque, para a maior parte dos jornaisfranceses produzidos noRio, os homens de nacionalidadefrancesa eram extremamente ignorantes em relação ao que acontecia no Império brasileiro e em sua capital. Assim, na tentativa de alterar esse cenáriovigenteeigualmenteparaqueelesconseguissemobteralgum sucesso em seus respectivos trabalhos, era preciso que os periódicos francesesajudassemaidentificarasoportunidadesoferecidaspelopaís e a tornar conhecidos os assuntos mais debatidos naquele momento, como, por exemplo, a política.

FoicomessemesmoargumentoqueoeditordoL'Échodel'Amerique du Sud, E. Sevène, informou que seu periódico teria grande empenho em manter a política entre suas anotações. A partir de"fontes credenciadas", ele registraria as "notícias políticas que incita[vam] no Brasil o

40 L'ÉCHO DE L'ATLANTIQUE, n. 1, 10 de janeiro de 1858, p. 1.

${ }^{41}$ L'AVENIR DU BRÉSIL: journal français. Rio de Janeiro, n. 1, 28 de novembro de 1885, p. 1. 
interesseea curiosidade"daspessoase"os discursos pronunciadosnas assembleias legislativas da Europa e dos Estados Unidos" a fim de trazer para seus leitores as discussões e as reflexões mais recentes realizadas em outros lugares. Os discursos e as seções do Senado e da Câmarados Deputados dolmpério do Brasil também ocupariam espaçonas páginasdojornaldeSevène,quetranscreveriaminuciosamenteosdebates,muitasdasvezesfervorosos, dessespolíticosbrasileirosdeentão. ${ }^{42}$

No decorrer do século XIX, a política, com seus homens e seus acontecimentos, recebeugrandeespaçonosimpressosfrancesesproduzidos na corte. Os dois Imperadores ganharam a maior parte das anotaçõesetiveram, porexemplo, seus discursosintegralmentetranscritos e traduzidos. Do mesmo modo, também foram legadas diferentesopiniõessobreasaçõesdosmonarcasesefaloudosacontecimentos da vida pessoal destes, daquilo que poderia ser entendido como algo pertencente à esfera particular, a saber: as festas dos casamentos, de aniversários, os passeios feitos a diversos lugares do país, entre outros registros queajudavam a construir, na maioria das vezes, uma imagem positiva dos dois monarcas perante a população da cidade do Rio ou quecontribuíam paraqueoscariocastivessemumamelhorcompreensão da situação doImpério, conformedestacou Altève Aumontemseu editorialdeprimeiraedição. Esseeditor, acercadetalassunto,informou que "cada número" de seu jornal conteria "um Boletim" com os "principais fatos políticos da semana" e que, igualmente, ofereceria"um rápido resumo das discussões e do trabalho do Senado e da Câmara dos Deputados - resumo a que não faltar[ia] interesse, no momento em que as paixões políticas monta[vam] os mais altos níveis da cólera".43

Somado à política, outro assunto que os editores franceses disseram de que iriam tratar em seus jornais e que também auxiliaria no conhecimento do Brasil era o comércio. Os franceses moradores da cidade do Rio de Janeiro, segundo Aumont, sempre precisavam de informações atualizadas do comércio carioca porque era com as ativi-

42 L'ÉCHO DE L'AMÉRIQUE DU SUD, n. 1, 30 de junho de 1827, p. 1.

${ }^{43}$ L'ÉCHO DU BRÉSIL ET DE L'AMÉRIQUE DU SUD, n. 1, 1 de maio de 1859, p. 1. 
dades comerciais que eles mais se envolviam naquele tempo. ${ }^{44} \mathrm{~A}$ parte comercial e financeira receberia um grande cuidado por parte do L'ÉchoduBrésiletdel'AmeriqueduSud,pois,segundoenfatizouseueditor, "nenhum jornal" teria dado até aquele momento

[...] de uma maneira contínua, imparcial e completa, informações cuidadosamenterecolhidas sobreasvariações da bolsa;resultandouma desordemeuma incerteza que são incontestáveis a muitas causas de desastres inesperados de falhasimprevistasquedesdemuitosanos colocamaperturbaçãodosafazeres. ${ }^{45}$

ParaAumont,eraincontornávelqueesseassuntofossetratadonas páginas de seu impresso, ainda mais pelofato de a colônia francesa no Rio de Janeiro sereminentemente comercial. Nesse sentido, comoobjetivo de realizar uma reforma completa na maneira como o assunto era veiculado pelos demais periódicos franceses da corte, o L'Écho du Brésil et del'AmériqueduSud, conformeo editor, publicaria"uma série de artigos" que ofereceria o verdadeiro cenário da diária "situação comercial e financeira do lugar", bem como também apresentaria algumas "tabelas de resumo das operações financeiras da semana". ${ }^{46} \mathrm{O}$ não conhecimento do mercado ou da verdadeira situação da bolsa de valores prejudicava os franceses, uma vez que o comércio não se comportava de maneira previsível. Estar informado das invariâncias e das incertezas dasatividadescomerciaise daeconomiadoBrasileraessencial para evitar uma desordem nos serviços prestados pelos franceses e, portanto, constituiria o principal assunto a ser abordado pelo editor dol'ÉchoduBrésiletdel'AmériqueduSud.AindadeacordocomAumont, essa característica particular de seu periódico deveria ser o que o dife-

\footnotetext{
${ }^{44}$ MARTINS, Ana Luiza Martins. Presença imigrante francesa no Brasil: entre visões do paraíso e mercado de trabalho e DUMONT, Juliette. Preciosos súditos, emigrantes atravancadores: a França e os franceses no Brasil no início do século XIX. In: VIDAL, Laurent. LUCA, Tania Regina de (orgs.). Op. Cit.

45 L'ÉCHO DU BRÉSIL ET DE L'AMÉRIQUE DU SUD, n. 1, 1 de maio de 1859, p. 1.

${ }^{46}$ L'ÉCHO DU BRÉSIL ET DE L'AMÉRIQUE DU SUD, n. 1, 1 de maio de 1859, p. 1.
} 
renciaria dos outros periódicos da corte, o que também justificaria sua produção no mundo dos impressos cariocas daquele tempo.

As novidades do comércio e das finanças da cidade do Rio de Janeiro, do Brasil e de outras partes do mundo já faziam parte das preocupaçõesdeoutrafolhafrancesa:oL'Échodel'AmeriqueduSud.Em 1827, o editor E. Sevène assinalou que seu impresso forneceria "os conceitos relevantes ao comércio da França, da Inglaterra e de outras nações com o Brasil". Isso se justificaria porque, conforme destacamos, o Brasil mantinha relações comerciais com a Inglaterra desde 1808 , quando abriu os portos às nações amigas, ${ }^{47}$ e com a França desde 1814, momento em que se estabeleceu o mencionado Tratado de Paz, e seus habitantes precisavam estar informados dos ocorridos no âmbito do setorcomercialedosacordos estabelecidosentreos países.

Ao longo de todo o Oitocentos, as atividades comerciais receberamgranderelevância nostextos deapresentação dessaspublicações francesas. Quarenta anos depois de Sevène, Louis Sauvages, do La GazetteduBrésil, registrou quetodosos trabalhadoresdacidadedoRio de Janeiro deveriam ser informados da dinâmica do mercado a fim de poderemgarantirprosperidadepara suasatividades. ${ }^{48}$ Segundooeditor, notícias sobre as chegadas e as partidas dos navios, os transportes demercadorias, as situações do mercado, as transações realizadas eos preços dos produtos sefariam correntes nas páginas de seu jornal,juntamente com as informações das"campanhas comerciais, financeiras e industriais" da França. Nas páginas do La Gazette du Brésil também apareceriam comentários das "casas bancárias", dos "estabelecimentos de créditos", das "companhias marítimas", das "sociedades comerciais", dos "sítios de construção naval", enfim, quaisquer informações que pudessem auxiliar e deixar os moradores da corte inteirados das novidades do comércio. ${ }^{49}$

\footnotetext{
${ }^{47}$ RICUPERO, Rubens. O Brasil no mundo. In: COSTA E SILVA, Alberto da. Crise colonial e Independência (1808-1830). Rio de Janeiro: Objetiva, 2011, p. 115-159. v. 1.

${ }^{48}$ LA GAZETTE DU BRÉSIL, n. 1, 23 de abril de 1867, p. 1.

${ }^{49}$ LA GAZETTE DU BRÉSIL, n. 1, 23 de abril de 1867, p. 1.
} 
Acerca do cuidado dos jornais franceses com as atividades comerciais, ao passo que o Rio de Janeiro crescia e se desenvolvia no século $\mathrm{XIX}$, as ruas do centro da cidade eram tomadas pelas casas comerciais dosmaisvariadosgêneroseviamchegarmercadoriasevendedoresde toda a sorte, modificando os costumes e alterando as convenções dos homens daquele tempo. Eram, em síntese, lojas de roupas, de calçados, perfumarias, chapelarias, joalherias, cabeleireiros, cafés, confeitarias e restaurantes, livrarias e tipografias, lojas de ferragens, farmácias, hotéis, armazéns de secos e molhados, entre outros tipos que evidenciavam um comércio bem variado e, de certo modo, especializado. ${ }^{50}$ Dessesestabelecimentoscomerciais, grandepartetinhacomoproprietárioos profissionaisestrangeiros, especialmenteingleses efranceses, que inspiravam os brasileiros mais sofisticados de então. Exclusivamente dentre os de nacionalidade francesa, as modistas eram as mais requisitadaspelasmulherescariocas, quedesejavamomelhorcorteeo melhor tecido da época. ${ }^{51}$ Com a intenção de oferecer os mais belos e perfeitostrabalhos, asmodistas precisavamimportaramaiorpartedos tecidos que eram utilizados, e as notícias das atividades comerciais e financeirasdasfolhasfrancesaspoderiammantê-lasinformadassobre achegada oua partida dos navios que traziam as mercadorias, ou mesmo anunciá-las aos moradores da cidade. É claro que não é possível afirmarqueasmodistasfrancesasseinteiraram dasinformaçõesoferecidaspelosperiódicosfranceses, entretantoregistraram-senelesmuitas das novidades do comércio deste tempo e lhes foram fornecidas notícias comerciais e financeiras que poderiam auxiliar os moradores do Rio imperial, como essas modistas.

A França, como era de esperar, também ocuparia as páginas dos jornais franceses, mas apareceria, segundo os editores, em um grau muito menor em relação aos assuntos do Brasil e da cidade do Rio de Janeiro. Para não deixar seus conterrâneos distantes dos eventos

${ }^{50}$ RIOSFILHO,AdolfoMorales delos.ORiode Janeirolmperial.Riode Janeiro:Topbooks, 2000, p.273-275.

${ }^{51}$ FREYRE, Gilberto. Vida social no Brasil nos meados do século XIX. Trad. Waldemar Valente em convênio com o Instituto Joaquim Nabuco de Pesquisas Sociais. São Paulo: Global, 2008, p. 50. 
do país natal, o editor do France et Brésil disse que seu jornal divulgaria as notícias da França a fim de contribuir para o estabelecimento de relações mais vantajosas entre as duas nações. ${ }^{52}$ Anos antes, Louis Sauvages, doLaGazetteduBrésil,seguindoessamesmaexpectativa,escreveu que "a colônia francesa estabelecida no Brasil" poderia contar com suas anotações porque ela seria útil a seus compatriotas, uma vez que traria "a pátria mãe ao conhecimento do país habitado por seus filhos emigrados". ${ }^{33}$ Além da França, de acordo com os textos dos editores, outros países igualmente deveriam ser lembrados pelos jornais franceses. Em 1858, os editores do L'Écho de l'Atlantique informaram que o periódico teria uma seção exclusiva "para notícias dos países europeus",54assimcomoAltèveAumont, doL'ÉchoduBrésiletdel'AmériqueduSud, que,em 1859, registrouqueofereceriainformaçõessobre a "Europa, a Ásia e a América" e que, especificamente acerca deste último continente, reuniria"todas as notícias importantes de Montevidéu, de Buenos Aires, do Uruguai, do Chile, do Peru, do Equador".55 De maneirageral, os periódicos franceses demonstravam quenoticiar países europeus, americanos ou asiáticos era imprescindível para que seusleitorescompreendessemosacontecimentosexternosaolmpério e analisassem as relações do Brasil com as demais nações do mundo, ainda que fosse preciso enfatizar que a atenção dada a este tema não pudessesercomparadaà do espaço reservadoà política eao comércio brasileiro.

Otemavariedadesocupavaquasesempreaúltimaseçãodasfolhas, sendo predecessor apenas dos anúncios. Segundo o editor do L'Écho duBrésiletdel'AmériqueduSud, seujornal teriauma partededicadaàs anedotas, àspiadas, àsles mots derires, ea algunsartigoscientíficos"de interessantes temas sobre o país". Nessa mesma seção seriam publicadosos mais novos romances da época, queestampariamo máximode

\footnotetext{
52 FRANCE ET BRÉSIL, n. 1, 2 de setembro de 1874, p. 1.

${ }^{53}$ LA GAZETTE DU BRÉSIL, n. 1, 23 de abril de 1867, p. 1.

${ }^{54}$ L'ÉCHO DE L'ATLANTIQUE, n. 1, 10 de janeiro de 1858, p. 1.

${ }^{55}$ L'ÉCHO DU BRÉSIL ET DE L'AMÉRIQUE DU SUD, n. 1, 1 de maio de 1859, p. 1.
} 
três páginas de um único número do jornal a cada mês. ${ }^{56}$ Por meio do periódico também havia ocomprometimento, conformeo registro de Sauvages, da realização de análises, relatórios e críticas detalhadas do "movimento da literatura e das artes", fazendo com que "os escritores brasileiros, os trabalhos científicos" e outras criações artísticas fossem amplamente divulgadas aos leitores. Por fim, alegou o editor, o La GazetteduBrésildivulgariaconstantementematériasarespeitodeartistas, pintores, músicosecantores, registrando-se tudo o que se pensava sobre os envolvidos com a arte e "dando-lhes a maior parte possível de publicidadepararegistrar"seusrespectivossucessos, quandoseexaltavam os bons e se depreciavam os ruins. ${ }^{57}$ Sevène, por sua vez, o editor dol'Échodel'AmeriqueduSud,informouquepublicariaemsuaseçãode variedades"muitosartigossobrequestõesdeinteressesgerais"afimde atrairleitorescom diferentespredileções. ${ }^{58}$ JáoCourrierdeBrésil,deAd. Hubert, comentou que traria escritos deliteratura, teatroe ciências, ou seja, textos de diferentes áreas de conhecimento, a fim de deixar seus leitores bem informados das novidades daquele tempo. ${ }^{59}$

Tal como os editores dos periódicos franceses destacaram as seções dedicadas aos assuntos de política, de comércio e de variedades -conformeapresentadoatéaqui-,algunsdelestambém comentaram sobre a importância da publicidade e dos anúncios para suas folhas periódicas e, consequentemente, para a divulgação de serviços e produtosaosleitores.AltèveAumont,editordoL'ÉchoduBrésiletdel'AmériqueduSud,escreveuqueapublicidadeconstituíaalgoessencialparaos impressosproduzidosnoRiode Janeirooitocentista, pois, segundoele, nesta cidade, mais do que em qualquer outro lugar do mundo, a publicidade "influencia[ria] a opinião pública". ${ }^{60}$ Outros editores franceses, embora não tenham sido tão explícitos quanto Aumont, disseram

\footnotetext{
${ }^{56}$ L'ÉCHO DU BRÉSIL ET DE L'AMÉRIQUE DU SUD, n. 1, 1 de maio de 1859, p. 1.

57 LA GAZETTE DU BRÉSIL, n. 1, 23 de abril de 1867, p. 1.

${ }^{58}$ L'ÉCHO DE L'AMÉRIQUE DU SUD, n. 1, 30 de junho de 1827, p. 1.

${ }^{59}$ COURRIER DU BRÉSIL: ce journal farait tous les dimanches. Rio de Janeiro, n. 1, 15 de setembro de 1854, p. 1.

${ }^{60}$ L'ÉCHO DU BRÉSIL ET DE L'AMÉRIQUE DU SUD, n. 1, 1 de maio de 1859, p. 1.
} 
que falariam de publicidade ou que estampariam anúncios em suas páginas finais, tendo-se em vista principalmente a função das peças de propaganda para os jornais. A título de exemplo, eles registraram, dependendo do periódico, que cada linha de um anúncio custava entre 60 e 200 réis, valor que pode ser considerado alto, pois o preço de somente um número de cada impresso era de aproximadamente 300 réis. Tais informações dão mostras de que a publicidade, além de ter um grande papel na propagação dos produtos e dos serviços existentes no Rio de Janeiro no século $\mathrm{XIX}_{,}^{61}$ parecia ser importante para a manutenção dos jornais - ou seja, o dinheiro dos anúncios ajudava a financiar sua produção. ${ }^{62}$

Oempenhodecomunicaraosleitoresnãocompetiaapenasaosescritosdas peçasdepropaganda,ostextospublicadosnasoutrasseções compartilhavam desta função, uma vez que o jornal era o principal meio de comunicação dos cariocas naquela época. Por esse motivo, os editores diziam que as notícias precisavam ser redigidas de um modo instigante, ou melhor, que os artigos não poderiam ser enfadonhos. Conforme destacou Fantasio, o editor do Le Gil-Blas, um jornal nunca deveria aborrecer seus leitores, os textos sempre os devem encantar como propósito demanteros existentese de conquistaroutrosmais. ${ }^{63}$ Seguindoessapostura,AltèveAumontassinalouqueoL'ÉchoduBrésilet del'AmériqueduSudprecisavaencontrarotomcorretoparaasuaescrita porqueumafolhafrancesa publicadalongedaFrança deveria seguiras exigênciasdo paísondeera produzida. Nãoerapossível,deacordocom esse editor, que seu jornal fosse redigido nos moldes dos jornais pro-

${ }^{61}$ MARTINS, Ana Luiza Martins. Imprensa em tempos de Império. In: MARTINS, Ana Luiza; LUCA, Tânia Regina de (org.). História da Imprensa no Brasil. São Paulo: Editora Contexto, 2012, p. 55.

62 Segundo a historiadora Isabel Lustosa"todos os jornais que apareceram no Rio de Janeiro, durante o período" de 1808 e 1823, quase sempre tinham anúncios em suas páginas finais, o que, segundo ela, contribuía para "o preço [de venda] do exemplar". LUSTOSA, Isabel. O nascimento da imprensa brasileira. Rio de Janeiro: Jorge Zahar, 2004, p. 63.

${ }^{63}$ LE GIL-BLAS, n. 1, 14 de outubro de 1877, p. 1. 
duzidos na França, ou mesmo na Europa; era necessário compreender queos públicos eram bem diferentes entreos doislados do Atlântico. ${ }^{64}$

A respeito dos leitores dos impressos franceses, embora não seja possível afirmar quem eles eram em razão da falta ou de pouca informação, de listas de assinantes, de números de tiragens ou de cartas de leitores, é muito provável que os jornais tenham chegado ao conhecimento detodos os homens letrados da corte, independentementede suasnacionalidades. Isso porque, foi muitocomumoaparecimentode artigos eanúncios escritos em língua portuguesa ou nos dois idiomas, ou mesma a publicação integral de uma outra folha francesa tanto em francêsquantoem português. Dequalquer maneira, a noçãodequeos jornaisfranceses deveriam conquistar, informare,consequentemente, levarproveitosaoscariocasoitocentistasfoiponto-chavedosdiscursos dos editores em seus editoriais de primeira edição. Tais discursos, do mesmo modo, podem ser vistos como indícios de uma época em que a imprensa - aqui com destaque para a do Rio imperial - assumiria o papel de principal veículo de informação daquele tempo.

Osassuntosqueoseditores disseramquererabordaremsuaspáginas denunciam, assim, o envolvimento queeles tiveramou desejavam ter com os acontecimentos da capital e de todo o Império. Falar da política e do comércio do Brasil, bem como dos países que tinham alguma relação com ele, foi uma maneira que os editores franceses encontraram para seus jornais se apresentarem como pertencentes à imprensa carioca oitocentista, embora tenham se qualificado, num primeiro momento, somente como da comunidade francesa.

\section{Conclusão}

Emsuma, os editoriais deprimeira ediçãodos periódicosfranceses publicados no Rio de Janeiro durante o século XIX, mais especificamente entre os anos de 1827 e 1896, evidenciam que seus respectivos editoresfrancesestinhamumalinhadeediçãomuitoparecida,conser-

${ }^{64}$ L'ÉCHO DU BRÉSIL ET DE L'AMÉRIQUE DU SUD, n. 1, 1 de maio de 1859, p. 1. 
vando-secomo diferença somenteo trato dado a um ou outroassunto ou pela maior ou menor atenção conferida a determinadas notícias. As apresentações seguiam certo padrão e procuravam destacar a importância dojornalao elencar os porquês deeles serem publicados na corte e os temas que mais deveriam ganhar a atenção para suas páginas. Quantoàestruturadasfolhas,elastambémerampensadascomseções muito parecidas, na maioria das vezes divididas em três ou quatro partes:uma primeira, destinadaaosassuntos de Brasil,com destaquepara a política interna e externa e para as atividades comerciais; outra, aos países da Europa, da América e da Ásia; e uma última, às variedades, onde eram publicados os romances, as piadas, as anedotas e as crônicas. Além disso, em geral, os editores das folhas francesas igualmente assinalavam que queriam oferecer um jornal agradável e útil, com notícias relevantes para os diferentes públicos leitores da corte.

Do mesmo modo, os textos podem ser vistos como indício da pre478 tensão alimentada pelos editores de contribuir de algum modo para o crescimento e desenvolvimento da cidade do Rio de Janeiro e de todo o Império do Brasil. Percorrendo tais enunciados, observamos comooseditoresesperavamqueseusimpressosfossemrecebidospelo públicoleitorque, muitoprovavelmente,conformeanalisado,eramuito maior que somente a comunidade francesa instalada na corte. De maneira geral, os periódicos franceses publicados na cidade do Rio de Janeiro no Oitocentos possivelmente compartilharam de muitas preocupações eobjetivos inerentes aos impressos brasileiros produzidos nessa época. Notamos, nesse sentido, que os assuntos que os editores franceses tratariam nas páginas de seus jornais diziam muito mais respeito ao funcionamento eàs novidades dolmpério do Brasilque sobre qualquer outra coisa. O propósito deste artigo, portanto, foi analisare dar a conhecer uma parte da imprensa carioca do século XIX, pouco considerada pelos estudiosos da imprensa neste período, por meio de uma análise dos editoriais de apresentação de cada uma das folhas francesas, e observar a que os editores visavam com seus impressos 
escritos inteiramente em francês e produzidos no Rio de Janeiro nos tempos do Império.

\section{Referências bibliográficas}

BERGER, Paulo. A Tipografia no Rio de Janeiro: impressores bibliográficos 1808-1900. Rio de Janeiro: Cia. Industrial de Papel Pirahy, 1984.

CANELAS, Letícia Gregório. O Courrier du Brésil e o conflito entre associações francesas no Rio de Janeiro. In: VIDAL, Laurent. LUCA, Tania Regina de (orgs.). Franceses no Brasil-séculos XIXeXX. SãoPaulo:Editora Unesp, 2012.

COSTA, Emília Viotti da. Da Monarquia à República:momentos decisivos. São Paulo: Editora UNESP, 2010.

COURRIER DU BRÉSIL: ce journal farait tous les dimanches. Rio de Janeiro, n. 1, 15 de setembro de 1854 .

FIGUEIREDO, Cláudio; SANTOS, Nubia Melhem; LENZI, Maria Isabel Ribeiro. O Porto e a cidade: o Rio de Janeiro entre 1565 e 1910. Editora: Rio de Janeiro; Casa da Palavra, 2005.

FONSECA, Gondim da. Biografia do Jornalismo Carioca (1808-1908). Rio de Janeiro: Livraria da Quaresma, 1941.

FRANCE ET BRÉSIL: journal français. Rio de Janeiro, n. 1, 2 de setembro de 1874.

FREYRE, Gilberto.Vida social no Brasil nos meados do séculoXIX.Trad.WaldemarValente em convênio com o Instituto Joaquim Nabuco de Pesquisas Sociais. São Paulo: Global, 2008.

HALLEWELL, Laurence. O Livro no Brasil: sua história. Trad. Maria da Penha Villalobos, Lólio Lourenço de Oliveira e Geraldo Gerson de Souza. São Paulo: EDUSP, 2012.

L'AVENIR DU BRÉSIL: journal français. Rio de Janeiro, n. 1, 28 de novembro de 1885.

L'ÉCHO DE L'ATLANTIQUE: organe des intérêts franco-brèsilliene, paraissant les dimanche et jeudi de chaque semaine. Rio de Janeiro, n. 1, 10 de janeiro de 1858.

L'INDÉPENDANT: feuille de commerce, politique, et litteraire. Rio de 
Janeiro, n. 1, 21 abril de 1827.

LA GAZETTE DU BRÉSIL: journal politique, commercial, agricole et littéraire. Rio de Janeiro, n. 1, 23 de abril de 1867.

LE GIL-BLAS: journal politique, satyrique et artistique. Rio de Janeiro, n. 1, 14 de outubro de 1877.

L'ÉCHO DE L'AMÉRIQUE DU SUD: journal politique, commercial e littéraire. Rio de Janeiro, n. 1, 30 de junho de 1827.

L'ÉCHO DU BRÉSIL ET DE L'AMÉRIQUE DU SUD: ce journal parait tous les dimanches. Rio de Janeiro, n. 1, 1 de maio de 1859.

LUSTOSA, Isabel. O nascimento da imprensa brasileira. Rio de Janeiro: Jorge Zahar, 2004.

MARTINS, Ana Luiza Martins. Imprensa em tempos de Império. In: ; LUCA, Tânia Regina de (org.). História da Imprensa no Brasil. São Paulo: Editora Contexto, 2012.

.Presença imigrante francesa no Brasil:entre visões do paraíso e mercado de trabalho. In: VIDAL, Laurent. LUCA, Tania Regina de (orgs.). Franceses no Brasil - séculos XIX e XX. São Paulo: Editora Unesp, 2012.

MENEZES, Pedro da Cunha; BANDEIRA, Júlio. O Rio de Janeiro na rota dos Mares do Sul. Rio de Janeiro: Andrea Jakobsson Estúdio, 2004.

MOLINA, Matías M. História dos jornais no Brasil: Da era colonial à Regência (1500-1840). São Paulo: Companhia das Letras, 2015.

NEVES, Lúcia Maria Bastos Pereira das. Livreiros franceses no Rio de Janeiro: 1799-1824. Disponível em: http://www.portcom.intercom.org.br/pdfs/ bb3aea30006796253008218e5bdda0c1.pdf. Acesso em: 30/05/2015.

PERUCHI,Amanda.Norastrodosjornaisfrancesesoitocentistas.Osanúnciosea vida social no Rio de Janeiro (1827-1896). 2016. 169 f. Dissertação (Mestrado em História). Faculdade de Ciências Humanas e Sociais, Universidade Estadual Paulista "Júlio de Mesquita Filho", Franca, 2016.

RICUPERO, Rubens. O Brasil no mundo. In: COSTA E SILVA, Albertoda.Crisecolonialelndependência(1808-1830).RiodeJaneiro:Objetiva, 2011, p. 115-159. v. 1.

RIOS FILHO, Adolfo Morales de los. O Rio de Janeiro Imperial. Rio de Janeiro: Topbooks, 2000.

Recebido: 29/03/2017 - Aprovado: 19/01/2018 